\title{
Neospora caninum immune mapped protein 1 (NcIMP1) is a novel vaccine candidate against neosporosis
}

\author{
Xia CUI, Daoyu YANG, Tao LEI, Hui WANG, Pan HAO, Qun LIU (凶) \\ Key Laboratory of Zoonosis of Ministry of Agriculture and National Animal Protozoa Laboratory, \\ College of Veterinary Medicine, China Agricultural University, Beijing 100193, China
}

\begin{abstract}
The Neospora caninum immune mapped protein 1 (NcIMP1) was identified as a membrane protein, and a previous study indicated that NcIMP1 could be a promising vaccine candidate against neosporosis. In this study, the immune response and protection efficacy of NcIMP1 were evaluated. The coding sequence of NcIMP1 was inserted into the eukaryotic expression vector pcDNA $3.1(+)$, resulting in the recombination plasmid pcDNAIMP1, which was used for the intramuscular immunization of $\mathrm{BALB} / \mathrm{c}$ mice. After immunization, the immune response was evaluated using a lymphoproliferative assay and cytokine and antibody measurements. Quantification of the cerebral parasite burden of mice challenged with $2 \times 10^{6} \mathrm{~N}$. caninum was performed 14 days after the last immunization. The results showed that the mice immunized with pcDNA-IMP1 developed a high level of specific antibody responses against recombinant NcIMP1, with a mixed IgG1/IgG2a response and a predominance of IgG2a production. The cellular immune response was associated with the production of IFN- $\gamma$, IL- 2 , IL-4 and IL10 cytokines. The experiment was terminated 30 days p.i., and the cerebral parasite burden in each mouse was assessed by quantitative PCR. The parasite burden was significantly reduced in the pcDNA-IMP1-vaccinated mice. These data suggest that IMP1 is a promising vaccine candidate against neosporosis.
\end{abstract}

Keywords Neospora caninum, immune mapped protein 1 (IMP1), vaccine candidate, BALB/c mice

\section{Introduction}

Neospora caninum is an obligate intracellular parasite,

Received January 30, 2015; accepted February 11, 2015

Correspondence: qunliu@cau.edu.cn which was initially reported as a protozoan in dogs with encephalomyelitis and myositis ${ }^{[1]}$. The parasite was first isolated and named in 1988 from a dog with hind limb paralysis $^{[2]}$. Also, N. caninum has been reported to infect various species of livestock including cattle, sheep, goats, deer, and horses ${ }^{[3-5]}$. Most importantly, $N$. caninum causes fetal abortion and neonatal mortality in cattle, and it has been responsible for significant economic losses to the livestock industry in endemic areas due to reproductive disorders $^{[6]}$.

Abortion, which is caused by N. caninum infections, is a major cause of economic loss to both the dairy and beef industries in China and other cattle producing countries of the world ${ }^{[7]}$. The economic impact of $N$. caninum infections of cattle has been estimated as \$26.6 million in annual losses in calf and milk production in Australia, $\$ 35.7$ million for the dairy industry in New Zealand and $\$ 27$ million per year in the $\mathrm{UK}^{[8]}$. In fact, high economic losses caused by neosporosis occur in many parts of the world. Therefore, a vaccine that provides sterile immunity against $N$. caninum infection is urgently needed.

Recently, considerable effort has been made to develop anti- $N$. caninum vaccines; however, most of these are protein-based vaccines. DNA-based vaccines have been used as potential candidates for protections because of their capacity to induce both humoral and cellular immunity. DNA-based vaccines have many important advantages, as they are generally safe and non-toxic. Therefore, we have focused on the development of DNA-based vaccines for neosporosis.

Immune mapped protein 1 (IMP1) was initially identified as a protective protein in Eimeria maxima, and it was thought to be conserved in apicomplexan parasites ${ }^{[9]}$. Fortunately, IMP1 in $N$. caninum strain $\mathrm{Nc} 1$ had been found in a previous study ${ }^{[10]}$. In that study, the NcIMP1 gene was identified as a novel membrane protein in $N$. caninum, and the anti-rNcIMP1 antibody could inhibit $N$. caninum tachyzoite invasion in an in vitro assay. It was 
speculated that NcIMP1 might be a potential vaccine candidate against neosporosis. Thus, the objectives of the present study were to examine the immunogenicity and protective efficacy of NcIMP1 in mice by constructing a eukaryotic plasmid, pcDNA-IMP1, which expresses IMP1, and to use this plasmid to evaluate the potential of IMP1 as a vaccine candidate against neosporosis in BALB/c mice challenged with $N$. caninum strain $\mathrm{Nc1}$.

\section{Materials and methods}

\subsection{Neospora caninum tachyzoites culture and purification}

N. caninum strain $\mathrm{Ncl}$ tachyzoites were maintained and passaged in African monkey kidney (Vero) cells that were cultured in Dulbecco's Modification of Eagle's Medium (DMEM) supplemented with L-glutamine, 8\% heatinactivated fetal bovine serum (Sigma, USA), penicillin $\left(100 \mathrm{U} \cdot \mathrm{mL}^{-1}\right)$ and streptomycin $\left(100 \mu \mathrm{g} \cdot \mathrm{mL}^{-1}\right)$ at $37^{\circ} \mathrm{C}$ in a $5 \% \mathrm{CO}_{2}$ air environment. Parasites were harvested and purified as described previously ${ }^{[7]}$. Parasites and host cell debris were washed in cold phosphate-buffered saline (PBS), and the final pellet was resuspended in cold PBS and syringed three times with a 27 -gauge needle. The parasites were then filtered through a $5.0 \mu \mathrm{m}$ pore filter (Millipore, USA), washed twice with PBS, and pelleted at $300 \times g$ for $10 \mathrm{~min}$.

\subsection{Construction of the eukaryotic expression plasmid}

The complete coding sequence of NcIMP1 (GenBank ${ }^{\mathrm{TM}}$ accession No. JN651092) was amplified by RT-PCR from the mRNA of $N$. caninum strain Nc1 using a pair of special primers (IMP1F, forward primer: AAGCTTGCCACCATGGGAGGCGTTTG CTCTAAAAG; IMP1R, reverse primer: TCTAGATTAGTGGTGGTGGTGGTGGTG CT). Hind III and $X b a$ I recognition sites were introduced and are underlined, and the italic oligonucleotide added before the ATG start site is a Kozak sequence. After purification, the RT-PCR product was double digested with Hind III and $X b a$ I (NEB, USA), and the fragment of IMP1 was cloned into the Hind III/Xba I sites of pcDNA3.1(+) (Invitrogen, USA). The resulting plasmid was named pcDNA-IMP1. The concentration of the plasmid was determined by spectrophotometry at OD 260 and $280 \mathrm{~nm}$.

\subsection{Expression of IMP1 in vitro}

HEK293 cells were transfected with pcDNA-IMP1 using electroporation as previously described for Toxoplasma gondii $^{111]}$. Briefly, $1 \times 10^{6}$ HEK293 cells were harvested and resuspended in DMEM containing $50 \mu \mathrm{g}$ pcDNAIMP1 plasmid and were electroporated in a $4 \mathrm{~mm}$ gap cuvette with a $210 \mathrm{~V}$ pulse. Electroporated cells were cultured at $37^{\circ} \mathrm{C}$ in a $5 \% \mathrm{CO}_{2}$ environment. Forty-eight hours after transfection, the cells were fixed with cool methanol for $20 \mathrm{~min}$, and IMP1 expression was detected using the indirect immunofluorescence assay (IFA), with a mouse anti-rNcIMP1 polyclonal antibody and a fluorescein isothiocyanate (FITC)-labeled goat anti-mouse IgG antibody (Proteintech Group Inc., Chicago) as a secondary antibody. Coverslips were observed under a digitalized fluorescence microscope IX71 (Olympus, Japan).

The expression of NcIMP1 in HEK293 cells was also identified by Western blot. The transfected HEK293 cells were cultured for $48 \mathrm{~h}$, and then harvested and boiled in $2 \times$ SDS-loading buffer (Beyotime Institute of Biotechnology, China) for $10 \mathrm{~min}$. Proteins of transfected cells were separated using a $12 \%(\mathrm{w} / \mathrm{v})$ SDS-PAGE gel. Following electrophoresis, the separated proteins were transferred onto polyvinylidene fluoride (PVDF) membranes (Millipore, USA). For western blotting analysis, the PVDF membrane was blocked with 5\% (w/v) skimmed milk diluted in PBS for $1 \mathrm{~h}$ at room temperature before incubation with mouse anti-rNcIMP1 antibody (diluted 1:750). After washing three times in PBST, the membrane was incubated with diluted goat anti-mouse IgG horseradish peroxidase (HRP)-labeled secondary antibody (1:10000; Sigma, USA) for $1 \mathrm{~h}$. Finally, proteins were visualized with ECL chemiluminescence reagents (CoWin Biotech Co., LTD., Beijing, China).

\subsection{DNA Immunization}

Specific-pathogen-free (SPF) grade female BALB/c mice aged six weeks were purchased from the Academy of Military Medical Sciences Laboratory Animal Center and were maintained under standard conditions with food and water ad libitum. All experimental procedures were conducted in accordance with the Chinese Laboratory Animal Administration Act 1988.

At the age of seven weeks, mice were randomly divided into four groups of 12 mice each, and the serological status (Neospora-negative) was checked by enzyme-linked immunosorbent assay (ELISA). The experimental mice were treated as follows. As a negative control, group I was intramuscularly injected with $100 \mu \mathrm{L}$ sterile PBS alone and remained uninfected throughout the experiment. As a positive control, group II was also treated with $100 \mu \mathrm{L}$ PBS and was infected intraperitoneally with $N$. caninum tachyzoites. Also as a control, group III was intramuscularly injected with $100 \mu \mathrm{L}$ empty pcDNA3.1(+) vector (at a concentration of $1 \mathrm{mg} \cdot \mathrm{mL}^{-1}$ ). Finally, group IV was intramuscularly injected with $100 \mathrm{~L}$ pcDNA-IMP (at a concentration of $1 \mathrm{mg} / \mathrm{ml}$ ). Mice were immunized using the same protocol on weeks 0,2 and 4 .

Blood was collected from the mouse tail vein prior to each immunization. Sera were separated and stored at $-20^{\circ} \mathrm{C}$ until used. 


\subsection{Assessment of antibody responses}

IgG antibody responses to NcIMP1 in mouse serum were measured by enzyme-linked immunosorbent assay (ELISA) as previously described for $T$. gondi ${ }^{[11]}$. Briefly, microtiter plates were coated with recombinant NcIMP1 (200 ng per well) in $50 \mathrm{mmol} \cdot \mathrm{L}^{-1}$ carbonate buffer $(\mathrm{pH}$ 9.6). After incubation overnight at $4^{\circ} \mathrm{C}$, nonspecific binding sites were blocked with $4 \%$ bovine serum albumin in PBS for $1 \mathrm{~h}$ at $37^{\circ} \mathrm{C}$. Serum samples diluted in PBS were added to the wells and incubated for $1 \mathrm{~h}$ at $37^{\circ} \mathrm{C}$. HRP conjugated goat anti-mouse IgG was used as the secondary antibody, and HRP conjugated goat anti-mouse IgG1 or IgG2a (Proteintech Group Inc., Chicago) was used for isotype analysis. Immune complexes were revealed by incubation with orthophenylene diamine and $0.15 \% \mathrm{H}_{2} \mathrm{O}_{2}$ in the dark for $20 \mathrm{~min}$. The reaction was stopped by the addition of $2 \mathrm{~mol} \cdot \mathrm{L}^{-1} \mathrm{H}_{2} \mathrm{SO}_{4}$, and the absorbance was measured at $450 \mathrm{~nm}$ using an ELISA reader (BioTekEL_680, USA). All samples were run in triplicate.

\subsection{In vitro lymphocyte proliferation studies}

Spleens were aseptically removed from mice (three per group) 2 weeks after the third immunization and were pressed through stainless steel mesh. Single-cell suspensions were obtained by filtration through nylon mesh to remove any tissue debris. After the red blood cells (RBCs) were removed using RBC lysis solution (Sigma), splenocytes were resuspended in RPMI1640 medium (GIBCO) supplemented with $10 \%$ fetal calf serum. Cells were then plated in 96-well Costar plates at a density of $2 \times 10^{5}$ cells per well and cultured in the presence of recombinant NcIMP1 $\left(10 \mu \mathrm{g} \cdot \mathrm{mL}^{-1}\right)$, concanavalin A (Con $\mathrm{A} ; 5 \mu \mathrm{g} \cdot \mathrm{mL}^{-1}$; Sigma) or medium alone (negative control) at $37^{\circ} \mathrm{C}$ in a $5 \% \mathrm{CO}^{2}$ environment. The proliferative activity was measured using a 3-(4,5-dimethylthylthiazol2-yl)-2,5-diphenyltetrazolium bromide (MTT, $5 \mathrm{mg} \cdot \mathrm{mL}^{-1}$, Sigma) dye assay, according to the method described by Bounous $^{[12]}$. The stimulation index (SI) was calculated as the ratio of the average OD $570 \mathrm{~nm}$ value of wells containing antigen-stimulated cells to the average OD 570 value of wells containing only cells with medium. All assays were performed in triplicate.

\subsection{Assessment of cytokine expression levels}

The detection of cytokines was performed according to the previously described method ${ }^{[13]}$. Splenocytes from immunized mice were cultured with different stimuli as described for the lymphoproliferation assay. Cell-free supernatants were harvested and assayed for interleukin2 (IL-2) and interleukin-4 (IL-4) activities at $24 \mathrm{~h}$, for interleukin-10 (IL-10) activity at $72 \mathrm{~h}$, and for gammainterferon (IFN- $\gamma$ ) activity at $96 \mathrm{~h}$. The IL-2, IL-4, IL-10 and IFN- $\gamma$ concentrations were evaluated using a commer- cial ELISA Kit according to the manufacturer's instructions (Dakewe Biotech, China). Cytokine concentrations were determined by reference to standard curves constructed with known amounts of mouse recombinant IFN$\gamma$, IL-2, IL-4 or IL-10. The sensitivity limits for the assays were $7.8 \mathrm{pg} \cdot \mathrm{mL}^{-1}$ for IFN- $\gamma, 32 \mathrm{pg} \cdot \mathrm{mL}^{-1}$ for IL-2, and $7.8 \mathrm{pg} \cdot \mathrm{mL}^{-1}$ for IL-4 and IL-10.

\subsection{Challenge infection and determination of cerebral parasite burden in mice}

Two weeks after the last immunization, with the exception of group I, all mice were challenged i.p. with $2 \times 10^{6}$ freshly purified $N$. caninum tachyzoites suspended in $200 \mu \mathrm{L}$ of PBS.

One month after the challenge, mice were sacrificed by $\mathrm{CO}_{2}$-enthanasia and their brains were removed. The cerebral parasite burden of the mice was determined by Neospora-specific quantitative real-time PCR of the Nc-5 sequence which is the specific sequence in $N$. caninum, using DNA binding SYBR Green (Takara, China). Host DNA was also quantified by quantitative real-time PCR on the 28S rRNA gene. Brain DNA extraction was performed using Dneasy Blood and Tissue Kit (TransGen, China) as previously described $^{[14]}$. The DNA concentrations in all brain samples were determined by UV spectrophotometry and were adjusted to $100 \mathrm{ng} \cdot \mu \mathrm{L}^{-1}$ with sterile DNase free water. The assessment of $N$. caninum tachyzoite loads is expressed as the number of tachyzoites per $100 \mathrm{ng}$ host DNA using absolute quantification based on standard curves of tachyzoite DNA and host tissue DNA ${ }^{[15]}$. The parasite counts were calculated by interpolation from a standard curve with DNA equivalents from 1000, 100, 10, 1 and 0.1 parasites included in each run.

\subsection{Statistical analysis}

All data were statistically analyzed by one-way analysis of variance (ANOVA). All statistical analyses were processed by the SPSS13.0 Data Editor software (SPSS Inc., Chicago, IL). The results from between-group comparison were considered to be significantly different if $P$ values were less than 0.05 .

\section{Results}

3.1 Identification of the expressed product by IFA and western blot

In vitro expression of pcDNA-IMP1 was evaluated by IFA at $48 \mathrm{~h}$ post-transfection. As shown in Fig. 1, green fluorescence was observed in HEK293 cells that were transfected with pcDNA-IMP1 (Fig. 1a), whereas no fluorescence was observed in the pcDNA3.1(+) transfected cells using antibodies against recombinant protein 
(a)

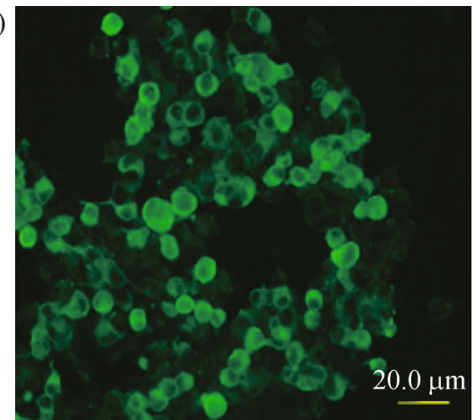

(b)

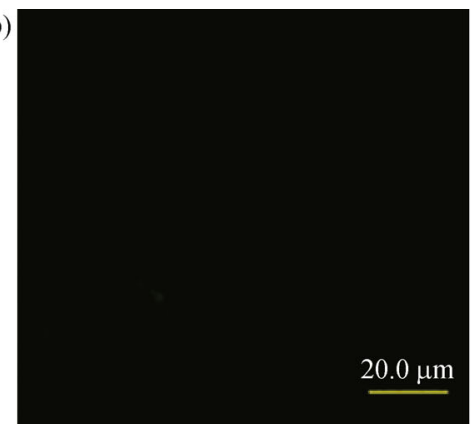

(c)

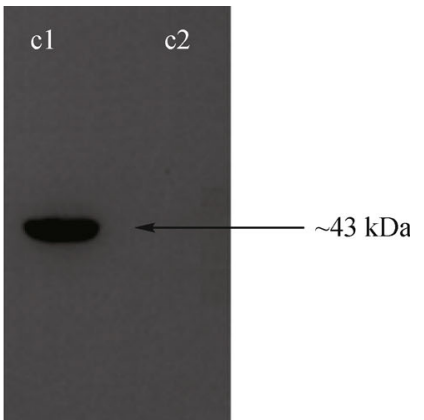

Fig. 1 Identification of the recombination plasmid pcDNA-IMP1. (a, b) The detection of IMP1 in HEK293 cells by IFAT. HEK293 cells were previously transfected with pcDNA-IMP1 (a) and the empty vector (b), and detected using mice anti-rNcIMP1 antibody and a FITClabeled goat anti-mouse IgG antibody; (c) expression analyses of IMP1 protein in transfected HEK293 cells by western blotting. The HEK293 cells transfected with pcDNA-IMP1 (lane c1) or untransfected control (lane c2) were analyzed by Western blotting.

NcIMP1 (Fig. 1b). The results of the Western blot showed that the anti-rNcIMP1 antibody could recognize a protein of about $43 \mathrm{kDa}$ when incubated with the lysates of HEK293 cells that were transfected with pcDNA-IMP1 (Fig. 1c).

\subsection{Humoral response}

To determine the levels of anti-NcIMP1 antibodies, all sera were tested by ELISA. As shown in Fig. 2, high levels of specific anti-IMP1 IgG antibodies were detected in the sera of mice immunized with pcDNA-IMP1, especially after the third immunization (the level of antibodies increased with successive immunizations). In contrast, mice injected with pcDNA $(+)$ alone or PBS did not generate antibodies against NcIMP1. Significant differences were found between the three groups (groups II, III and IV) $(P<0.05)$.
3.3 Specific anti-IMP1 IgG subclass induced by DNA vaccination

To characterize whether a Th1 and/or Th2 immunology response was elicited in immunized mice, the distribution of IgG subtypes IgG1 and IgG2a, specific for rNcIMP1, was analyzed. A mixed $\operatorname{IgG} 1 / \operatorname{IgG} 2 \mathrm{a}$ response with predominant $\operatorname{IgG} 2$ a production was detected in the sera mice immunized with pcDNA-IMP1 (Fig. 3). These results indicated a shift toward the Th1-type response.

\subsection{Cellular proliferative response induced by DNA vaccination}

The splenocytes from mice that were immunized with pcDNA-IMP1, or empty plasmid pcDNA3.1 $(+)$ or PBS, were prepared 2 weeks after the third immunization to

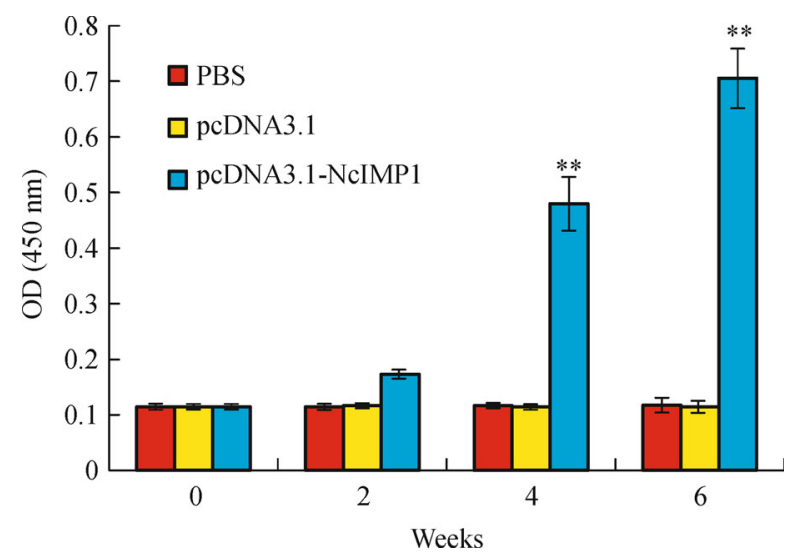

Fig. 2 The dynamic of the antibody response induced by DNA vaccine immunization. Determination of specific anti-IMP1 IgG in the sera of BALB/c mice immunized with pcDNA-IMP1, pcDNA [pcDNA 3.1(+)] or PBS under the same condition. Results are expressed as mean of the OD $450 \pm \mathrm{SE}(n=5)$. **, $P<0.05$. 


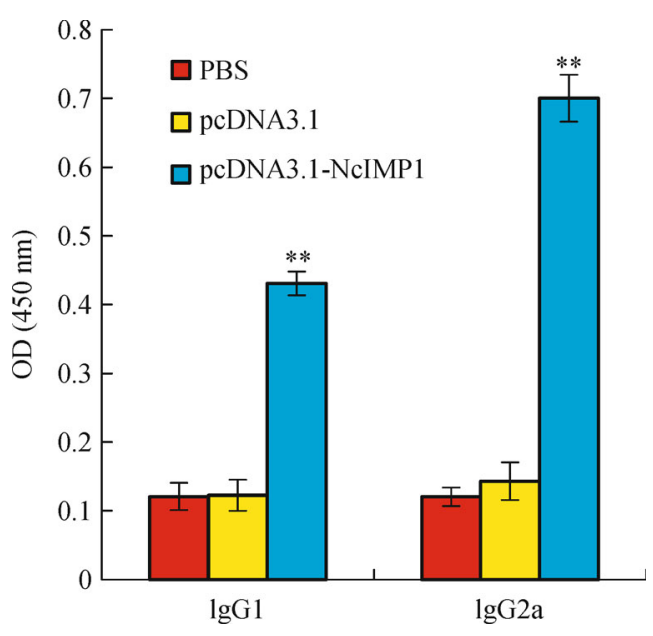

Fig. 3 Distribution of IgG subtypes IgG1 and IgG2a specific for rTgIMP1 was analyzed by ELISA. Results are expressed as mean of the OD $450 \pm \operatorname{SE}(n=5)$.**, $P<0.05$.

assess the proliferative immune responses to rNcIMP1. The splenocytes from mice immunized with pcDNA-IMP1 had a slight but significant proliferation response to rNcIMP1. In contrast, splenocytes from mice immunized with control plasmid pcDNA3.1(+) did not proliferate when stimulated with rNcIMP1 (Table 1).

\subsection{Cytokine production}

The supernatants of splenocytes cultured from mice that were immunized with pcDNA-IMP1, pcDNA3.1 $(+)$ or PBS were harvested at different time points, after restimulation with $\mathrm{rNcIMP} 1$, and assessed for the production of IFN- $\gamma$, IL-2, IL-4 and IL-10 (Table 1). Large amounts of IFN- $\gamma$ were produced in the supernatants of re-stimulated splenocyte cultures from mice that were immunized with pcDNA-IMP1, but no specific production of IFN- $\gamma$ was observed in groups injected with PBS or pcDNA3.1(+). Specific amounts of IL-2 and IL-10 were also synthesized by the re-stimulated splenocytes from the mice immunized with pcDNA-IMP1. Significant differences were found in IFN- $\gamma$, IL-2, IL-4 and IL-10 production compared with that of the other groups that were immunized with empty plasmid or PBS.

\subsection{Cerebral parasite burden in experimental groups}

To test whether DNA vaccination induced effective protection against $N$. caninum infection, the immunized mice were challenged with $2 \times 10^{6} \mathrm{Nc} 1$ tachyzoites 2 weeks after the last immunization. Then, we compared the cerebral parasite burden in mice by quantitative PCR (Table 2). Vaccination with pcDNA-IMP1 resulted in a significant $(P<0.05)$ reduction in the numbers of

Table 1 Cytokine production by splenocytes of immunized BALB/c mice after immunization by pcDNA-NcIMP1

\begin{tabular}{|c|c|c|c|c|c|}
\hline \multirow{2}{*}{ Groups } & \multicolumn{4}{|c|}{ Cytokine production $/\left(\mathrm{pg} \cdot \mathrm{mL}^{-1}\right)$} & \multirow{2}{*}{ Proliferation $\mathrm{S}$} \\
\hline & IFN- $\gamma$ & IL-2 & IL-4 & IL-10 & \\
\hline PBS & $49.22 \pm 2.32 \mathrm{a}$ & $48.26 \pm 2.51 \mathrm{a}$ & $49.09 \pm 4.57 \mathrm{a}$ & $51.28 \pm 4.35 \mathrm{a}$ & $0.76 \pm 0.078 \mathrm{a}$ \\
\hline pcDNA & $52.00 \pm 3.78 \mathrm{a}$ & $50.00 \pm 10.58 \mathrm{a}$ & $52.84 \pm 4.22 \mathrm{a}$ & $53.24 \pm 5.861 \mathrm{a}$ & $0.78 \pm 0.079 \mathrm{a}$ \\
\hline PcDNA-IMP1 & $971.92 \pm 27.75 b$ & $604.38 \pm 16.05 b$ & $217.27 \pm 6.86 b$ & $298.33 \pm 33.75 b$ & $2.317 \pm 0.087 b$ \\
\hline
\end{tabular}

Note: The same letter mean no difference $(P>0.05)$, whereas different letters mean significant difference $(P<0.05)$.

Table 2 BALB/c mice brain burden of $N$. caninum

\begin{tabular}{lc}
\hline Groups & Cerebral parasite burden (tachyzoites per 100 ng) \\
\hline Positive control & $44.22 \pm 0.28 \mathrm{a}$ \\
Negative control & $0.08 \pm 0.01 \mathrm{~b}$ \\
pcDNA & $40.32 \pm 0.24 \mathrm{a}$ \\
pcDNA-IMP1 & $0.09 \pm 0.04 \mathrm{~b}$ \\
\hline
\end{tabular}

Note: The same letter mean no difference $(P>0.05)$, whereas different letters mean significant difference $(P<0.05)$. 
tachyzoites compared with the mice that were vaccinated with PBS or pcDNA3.1(+) alone. Furthermore, pcDNAIMP2 vaccination yielded similar results to those from the negative control mice, which were immunized only with PBS without a $N$. caninum challenge. These results indicate that immunization with pcDNA-IMP1 could effectively protect mice against $N$. caninum infection.

\section{Discussion}

In this study, we have demonstrated that a DNA vaccine that encodes a novel target antigen, IMP1 of $N$. caninum, is a simple and potent vaccine that elicits a strong specific humoral and cellular immune response, which also provides significant protection against $N$. caninum infection.

In recent years, encouraging progress has been made in the identification of vaccine candidates against $N$. caninum infection. These antigens included the dense granule protein GRA7, rhoptry antigen ROP2, microneme proteins (MIC1, MIC3, and MIC4), and surface antigens (SAG1, SGA4 and SRS2) ${ }^{[16-18]}$. In the present study the protective effect against $N$. caninum infection of a DNA vaccine based on the NcIMP1 gene was evaluated in mice. The results showed that immunization with pcDNA-IMP1 induced a high level of humoral antibodies and a mixed IgG1/IgG2a response, with a predominance of IgG2a production. Compared with control groups, immunization with pcDNA-IMP1 enhanced Th1-mediated immunity with a high level of IL-2 and IFN- $\gamma$ in the sera of vaccinated mice. In addition, as an indication of a Th2-type immune response, a slight increase of cytokine IL-4 was also observed. Therefore, these results demonstrated that pcDNA-IMP1 could elicit strong humoral and cellular Th1 immune responses, which is essential for cell-mediated immunity and resistance against intracellular pathogens.

The membrane proteins, such as NcSAG1 and NcSRS2, which participate in host cell invasion, have been studied as potential vaccine candidates and have proven to be capable of inducing protective immunity against $N$. caninum infection ${ }^{[19-22]}$. NcIMP1 was identified as a membrane protein, and furthermore, anti-rNcIMP1 could inhibit host cell invasion. In the present study, we demonstrated that $N$. caninum IMP1 could induce specific humoral and cellular responses that are capable of protecting mice against $N$. caninum infection.

The present result is similar to that of a previous study, in which immunization with $E$. maxima IMP 1 recombinant protein could reduce oocyst output by $45 \%$ in experimentally infected chickens ${ }^{[9]}$; and immunization with a $T$. gondii IMP1-derived DNA vaccine, pcDNA-TgIMP1, could prolong the survival time of mice challenged with T. gondii tachyzoites ${ }^{[11]}$. In the present report, the cerebral parasite burden of mice immunized with pcDNA-NcIMP1, which could express $N$. caninum IMP1 protein, was significantly decreased compared with that of the positive control mice. The cerebral parasite burden level was similar to that of the negative control mice. Therefore, we speculate that IMP1 is a promising vaccine candidate for other apicomplexan parasites.

\section{Conclusions}

The present study evaluated the immunogenicity and protective potency of a DNA-based vaccine that expresses NcIMP1. This vaccine was able to elicit significant humoral and cellular Th1 immune responses, which significantly decreased the cerebral parasite burden level in BALB/c mice challenged with $N$. caninum tachyzoites compared with that of controls. Finally, we conclude that the use of plasmid DNA that encodes the IMP1 of $N$. caninum offers a promising approach as a vaccine against neosporosis.

Acknowledgements This study was supported by National Key Basic Research Program of China (2015CB150300) and Beijing Municipal Natural Science Foundation (6131001)

Compliance with ethics guidelines Xia Cui, Daoyu Yang, Tao Lei, Hui Wang, Pan Hao and Qun Liu declare that they have no conflict of interest or financial conflicts to disclose.

All applicable institutional and national guidelines for the care and use of animals were followed.

\section{References}

1. Bjerkås I, Mohn S F, Presthus J. Unidentified cyst-forming sporozoon causing encephalomyelitis and myositis in dogs. Zeitschrift fur Parasitenkunde, 1984, 70(2): 271-274

2. Dubey J P, Hattel A L, Lindsay D S, Topper M J. Neonatal Neospora caninum infection in dogs: isolation of the causative agent and experimental transmission. Journal of the American Veterinary Medical Association, 1988, 193(10): 1259-1263

3. Dubey J P, Lindsay D S. A review of Neospora caninum and neosporosis. Veterinary Parasitology, 1996, 67(1-2): 1-59

4. Dubey J P. Review of Neospora caninum and neosporosis in animals. Korean Journal of Parasitology, 2003, 41(1): 1-16

5. Dubey J P, Schares G. Neosporosis in animals - the last five years. Veterinary Parasitology, 2011, 180(1-2): 90-108

6. Dubey J P, Schares G, Ortega-Mora L M. Epidemiology and control of neosporosis and Neospora caninum. Clinical Microbiology Reviews, 2007, 20(2): 323-367

7. Zhang W, Deng C, Liu Q, Liu J, Wang M, Tian K G, Yu X L, Hu D M. First identification of Neospora caninum infection in aborted bovine foetuses in China. Veterinary Parasitology, 2007, 149(1-2): $72-76$

8. Reichel M P, Alejandra Ayanegui-Alcérreca M, Gondim L F P, Ellis $\mathrm{J}$ T. What is the global economic impact of Neospora caninum in cattle- the billion dollar question. International Journal for Parasitology, 2013, 43(2): 133-142 
9. Blake D P, Billington K J, Copestake S L, Oakes R D, Quail M A, Wan K L, Shirley M W, Smith A 1. Genetic mapping identifies novel highly protective antigens for an apicomplexan parasite. PLoS Pathogens, 2011, 7(2): e1001279.

10. Cui X, Lei T, Yang D Y, Hao P, Liu Q. Identification and characterization of a novel Neospora caninum immune mapped protein 1. Parasitology, 2012b, 139(8): 998-1004

11. Cui X, Lei T, Yang D, Hao P, Li B, Liu Q. Toxoplasma gondii immune mapped protein-1 (TgIMP1) is a novel vaccine candidate against toxoplasmosis. Vaccine, 2012, 30(13): 2282-2287

12. Bounous D I, Campagnoli R P, Brown J. Comparison of MTT colorimetric assay and tritiated thymidine uptake for lymphocyte proliferation assays using chicken splenocytes. Avian Diseases, 1992, 36(4): 1022-1027

13. Zhao Z, Ding J, Liu Q, Wang M, Yu J, Zhang W. Immunogenicity of a DNA vaccine expressing the Neospora caninum surface protein NcSRS2 in mice. Acta Veterinaria Hungarica, 2009, 57(1): 51-62

14. Müller N, Vonlaufen N, Gianinazzi C, Leib S L, Hemphill A. Application of real-time fluorescent PCR for quantitative assessment of Neospora caninum infections in organotypic slice cultures of rat central nervous system tissue. Journal of Clinical Microbiology, 2002, 40(1): 252-255

15. Debache K, Guionaud C, Alaeddine F, Mevissen M, Hemphill A. Vaccination of mice with recombinant NcROP2 antigen reduces mortality and cerebral infection in mice infected with Neospora caninum tachyzoites. International Journal for Parasitology, 2008, 38(12): 1455-1463

16. Nishikawa Y, Zhang H, Ikehara Y, Kojima N, Xuan X, Yokoyama N. Immunization with oligomannose-coated liposome-entrapped dense granule protein 7 protects dams and offspring from Neospora caninum infection in mice. Clinical and Vaccine Immunology, 2009, 16(6): 792-797

17. Nishikawa Y, Xuan X, Nagasawa H, Igarashi I, Fujisaki K, Otsuka $\mathrm{H}$, Mikami T. Prevention of vertical transmission of Neospora caninum in $\mathrm{BALB} / \mathrm{c}$ mice by recombinant vaccinia virus carrying NcSRS2 gene. Vaccine, 2001, 19(13-14): 1710-1716

18. Pinitkiatisakul S, Friedman M, Wikman M, Mattsson J G, LövgrenBengtsson K, Ståhl S, Lundén A. Immunogenicity and protective effect against murine cerebral neosporosis of recombinant NcSRS2 in different iscom formulations. Vaccine, 2007, 25(18): 36583668

19. Cannas A, Naguleswaran A, Müller N, Eperon S, Gottstein B, Hemphill A. Vaccination of mice against experimental Neospora caninum infection using NcSAG1- and NcSRS2-based recombinant antigens and DNA vaccines. Parasitology, 2003, 126(Pt 4): 303312

20. Haldorson G J, Mathison B A, Wenberg K, Conrad P A, Dubey J P, Trees A J, Yamane I, Baszler T V. Immunization with native surface protein NcSRS2 induces a Th2 immune response and reduces congenital Neospora caninum transmission in mice. International Journal for Parasitology, 2005, 35(13): 1407-1415

21. Haldorson G J, Stanton J B, Mathison B A, Suarez C E, Baszler T V. Neospora caninum: antibodies directed against tachyzoite surface protein NcSRS2 inhibit parasite attachment and invasion of placental trophoblasts in vitro. Experimental Parasitology, 2006, 112(3): 172-178

22. Tuo W, Zhao Y, Zhu D, Jenkins M C. Immunization of female BALB/c mice with Neospora cyclophilin and/or NcSRS2 elicits specific antibody response and prevents against challenge infection by Neospora caninum. Vaccine, 2011, 29(13): 2392-2399 